\title{
Os frades de \\ Boaventura na \\ Cidade dos Homens: \\ os franciscanos e a \\ concepção monástica \\ de Agostinho
}

\section{Bonaventure's friars at Men's City: the Franciscans and Augustine's monastic conception}

\section{Resumo}

Boaventura de Bagnoregio (1217-1274), ministro-geral da Ordem Franciscana (1257-1274) e mestre de Teologia na Universidade de Paris, é considerado um importante herdeiro do pensamento agostiniano, e imprimiria essa característica à sua Ordem e ao conjunto de sua produção. Agostinho considerava o homem como um ser limitado por sua natureza pecadora a partir da Queda, mas reconhecia a possibilidade da reconciliação com o Criador por meio da ação humana no mundo, indiferentemente aberto às duas Cidades. Boaventura, por sua vez, concebeu seus frades como representação da condicão peregrina do homem no mundo, e a pobreza - assim como o conhecimento -, como uma via para a perfeição evangélica e para a redenção dos homens. Neste capítulo, procuraremos demonstrar a forma pela qual a concepção agostiniana do homem e de sua trajetória no mundo foi assimilada por Boaventura e serviu como base para o modelo franciscano de cristão.

Palavras-chave: Pecado e queda, Ordens religiosas, representação.

\section{Abstract}

Bonaventure of Bagnoregio (1217-1274), Minister General of the Franciscan Order (1257-1274) and Master of Theology at the University of Paris, is considered an important heir of Augustinian thought, and would imprint this characteristic to his Order and to the whole of his 
production. Augustine considered humanity as beings limited by their sinful nature since from Fall, but he recognized the possibility of reconciliation with the Creator through human action in the world, indifferently open to both Cities. Bonaventure, in turn, conceived his friars as a representation of the pilgrim condition of mankind in the world, and poverty - as well as knowledge - as a way to evangelical perfection and men's redemption. In this chapter we will try to demonstrate how the Augustinian conception of man and his trajectory in the world was assimilated by Bonaventure and served as the basis for the Franciscan Christian model.

Keywords: Sin and fall, Religious orders, Representation.

\section{Introdução}

Ao fato conhecido da adoção do modelo agostiniano pela Ordem Dominicana, em princípios do século XIII - os frades de Domingos organizaram-se como cônegos, com as decorrências jurídicas daí decorrentes -, apõe-se a assimilação, por parte da Ordem Franciscana, de um amplo conjunto de acepções agostinianas, ao qual daremos o nome de concepção. A totalidade dessas ideias pode ser notada, de forma difusa embora explícita, no conjunto das ideias e práticas veiculadas dentro da Ordem e a partir dela, e liga-se, sobretudo, à atuação de Boaventura e ao alcance de suas ideias - estas muitas vezes coincidem com a própria noção de "pensamento franciscano". Ressalte-se que não há oposição entre os dois fenômenos, a saber, a "agostinização" dos pregadores e aquela dos mendicantes: ao passo que os primeiros se ligaram a Agostinho pela adoção de um modelo primariamente formal - a Regra - e passível de percepção imediata, os segundos assimilaram uma espécie de "agostinismo difuso", traduzido em sua visão de mundo e em sua autorrepresentação como frades - trata-se de concepções sobre a Criação e humanidade, e sobre o papel dos "santos homens", os religiosi, na Igreja Militante - aquela forçosamente imersa no mundo e identificada à condição humana na Terra.

\section{Agostinho e o pecado: sobre a natureza humana e suas implicações}

No paradigma monástico oriental, construído a partir do século IV em conformidade com a própria formação do monasticismo cristão, sobressaiam o rigor ascético e a concepção do monge como ser angélico, a religar-se ao estado primevo da humanidade. Derivado de concepções pitagóricas, clássicas e judaicas (PACAUT, 1993, p. 9) o estado do monge - monachare (CONSTABLE, 2002, p. 7) - implicava, para os primeiros padres do deserto - entre a Palestina e o Egito romanos - no exercício de uma existência situada no limite do humano, e que deveria alçar o seu praticante à condição angélica.

O modo de vida praticado por aqueles monges deveria cumprir a profecia da recuperação do estado angélico da humanidade, a qual, tendo sido criada nos céus na qualidade de anjos, havia decaído a partir do Pecado Original. De acordo com essa tradição (BROWN, 1989, p. 277 e seguintes), Adão e Eva partilhariam de uma condição assexuada no Jardim do Éden, tendo, somente a partir da Queda, assumido as suas sexualidades e destas usufruído para fins de reprodução e prazer. A profecia do "paraíso reconquistado" - que supunha a reconciliação dos homens com sua natureza original - coadunava-se com o ideal paulino da "simplicidade do coração", a ser atingido pela superação das preocupações próprias do coração duplo - que caracterizavam o casamento e a vida doméstica e que correspondiam à essência da existência no "mundo". A esses elementos acrescentava-se a paisagem natural do deserto, lugar geográfico e, ao mesmo tempo, representação (BROWN, 2008, p. 217 e seguintes) da via contemplationis dos monges - e sua emulação do retorno à natureza humana assexuada.

A clivagem fundamental dava-se pela oposição entre o deserto e o mundo, sendo o primeiro reduto da vida angélica, e o segundo, palco da ação do kosmikos, o homem imerso no século e nos valores mundanos. O kosmikos encontrava-se 
imerso na sociedade, carecendo de liberdade para "dar-se a Cristo" (BROWN, 2007, p. 173). Entre os kosmikoi, encontravam-se mulheres e homens laicos, mas também bispos e sacerdotes, pois o "[...] mundo como um todo se encontrava ensombrecido pela presença dos santos homens de vida angélica, associados ao deserto" (BROWN, 2007, p. 173). No deserto, tanto o real quanto o representado, os ascetas - por meio de rigorosos jejuns, castigos corporais autoinfligidos e cumprimento de pesados trabalhos físicos - recuperariam a glória perdida do Paraíso adâmico.

Em sua transposição ao Ocidente e o clero latinos, o problema da sexualidade assumiria contornos específicos, sobretudo a partir de sua reelaboração por Santo Agostinho (354430). Em sua contestação ao maniqueísmo - ao qual aderira nos primeiros escritos -, o bispo de Hipona conferiria novo sentido à questão, assumindo relativa - tanto quanto sutil - defesa da materialidade. Para Agostinho, a sociedade humana, que compreendia necessariamente o casamento e a sexualidade, não poderia ser considerada como essencialmente ruim, mas somente inferior à sociedade paradisíaca, da qual partilharam Adão e Eva. Estes, como decorrência dessa formulação, eram apresentados como seres sexuados - e não angélicos -, sendo o Paraíso caracterizado não pela ausência da sociedade estabelecida - como queriam os padres do Oriente em relação ao deserto -, mas antes a sociedade estabelecida em sua idealidade. Assim, sendo o Paraíso um estado plenamente social - e não propriamente a antítese da vida mundana -, sua reconquista se abria tanto ao silêncio do deserto quanto à hierarquia da Igreja estabelecida nas cidades:

E uma parte desse paraíso reconquistado pode estar ligado não simplesmente ao abandono público e total do casamento pelo deserto, e sim ao intenso esforço privado dos cônjuges para elevar sua conduta sexual à altura da harmoniosa inocência da qual Adão e Eva deram o exemplo com sua sexualidade conjugal (BROWN, 1989, p. 294).
Em sua reflexão acerca da sociedade adâmica - De civitate Dei, L.XIV, cap. 10 -, Agostinho enuncia a instituição do matrimônio, originado em Deus e consistindo no laço social fundamental do Paraíso terrestre. O matrimônio, que cimentou a ligação entre o primeiro homem e a primeira mulher, fundava a sociedade primitiva ao mesmo tempo em que ratificava a natureza sexual dos Pais da Humanidade.

A crítica de Agostinho à perspectiva monástica "original" comportou derivações tais como a ruptura com a moral estoica da "distância social" (BROWN, 1989, p. 298), associada ao decoro das camadas sociais superiores - fator de diferenciação e distanciamento dos cidadãos em relação a seus inferiores e às mulheres. A fraqueza moral, traço constitutivo da natureza humana, extinguia as categorias da sociedade romana, recolocando a humanidade sobre um ideal de universalidade.

A consciência de uma fraqueza moral inescapável ao homem, porque inseparável de sua natureza, reconciliava o deserto e a cidade, com o consequente esmaecimento de suas fronteiras. Doravante, observar-se-ia, no Ocidente, a recorrência da formação monástica no interior da classe episcopal, a partir de uma dinâmica que acentuava o trânsito entre o monastério e a diocese. Markus (1997, p. 199) assinalou essa fragilidade de limites ao concluir que os monastérios - sobretudo no Sul da Gália - ter-se-iam convertido em "reservatórios de episcopáveis". Os bispos, autoridades fundadoras da fides christiana no mundo romano, recuperavam sua condição de excelência de costumes: "[...] formado em comunidades monásticas, o clero casto governa os leigos: cabem a eles a disciplina e o conselho quanto à anomalia perpétua e partilhada de uma sexualidade decaída" (BROWN, 1989, p. 298).

A renúncia não poderia, portanto, elevar alguém acima da natureza sexual do homem: essa era o "[...] mínimo denominador comum da grande democracia de pecadores reunidos na Igreja Católica" (BROWN, 1989, p. 299). Na Igreja Ocidental, prevaleceria a batalha pela castidade - a mais difícil luta do homem, uma 
vez que contrariava a sua própria natureza. Nesse sentido, a Queda equalizava os homens na sociedade, colocando em relevo sua condicão fundamental de pecadores. Brown (1989, p. 259) refere-se à solidariedade no interior da basílica cristã, frequentada por todos e destituída de espaços distintivos - fatores de oposição aos templos romanos e às sinagogas -, em que o elo comum entre os cristãos era - pecado, e os aspectos que distinguiam as categorias necessariamente partiam desse pressuposto inevitável. Agostinho estabelecia, em suas Confissões - Confessiones, L.I, cap. 11 -, o alcance e a profundidade do pecado original na constituição da natureza humana: "A inocência da criança reside na fragilidade dos membros, não na alma".

\section{A Cidade Terrestre e a Cidade Celeste: o homo viator no Reino de Deus}

O encontro do Ocidente com os padres do deserto seria, todavia, favorável à influência da concepção monástica sobre a cultura e os padres latinos. Essa permeabilidade não demoraria a se manifestar, de modo que o fenômeno encontraria os seus caminhos de difusão na Península Itálica ainda no século IV, a partir do exílio do bispo Atanásio e de outros sacerdotes alexandrinos.' A Epístola 127 de São Jerônimo mencionaria os padres refugiados em Roma e sua consequente influência sobre vários cristãos de elevada posição social. ${ }^{2} \mathrm{O}$ célebre escrito de Atanásio, a Vita de Santo Antônio do Egito, moldaria a primeira

Atanásio, bispo de Alexandria, instalar-se-ia em Roma em função da disputa com o partido ariano, no contexto imediatamente posterior ao Concílio de Niceia (325), no qual obtivera, junto ao imperador Constantino, vitória na discussão sobre a natureza de Cristo - da qual resultaria o estabelecimento do dogma da consubstancialidade das pessoas da Trindade e a anatematização do cristianismo ariano.

2 A respeito da perspectiva dos padres da Igreja latina acerca dos acontecimentos dos séculos IV e $\mathrm{V}$ Batalha de Adrianópolis (378), saque de Roma (410) e, em contrapartida, a ascensão da vida eremítico-contemplativa -, ver Pereira (2013, p. 11-26). percepção do Ocidente acerca do fenômeno. Laico ainda, Agostinho entraria em contato com o monasticismo, a julgar pela impressão descrita nas Confissões, em que afirmava que em Milão havia um mosteiro repleto de bons irmãos, sob o patrocínio do bispo Ambrósio. Ali, na condição de estudante e discípulo de Ambrósio, teria elaborado projetos de vida em comum - Confessiones, L.VI, cap. 24:

\begin{abstract}
Éramos muitos os amigos que, sentindo aversão pelos aborrecimentos e tumultos da vida social, tínhamos discutido, projetado, e já quase decidido, nos retirar para viver em meditação, longe do mundo dos homens. Tínhamos organizado nosso retiro, de modo a pôr em comum todos os bens que possuíamos, formando, assim, um patrimônio único.
\end{abstract}

Ao tornar-se bispo de Hipona, dedicar-se-ia à proteção e ao fomento às comunidades religiosas, tendo redigido duas regras para a vida em comum. ${ }^{3}$ É de sua autoria reconhecida, ainda, uma obra sobre o trabalho dos monges - intitulada De opere monachorum. Naqueles escritos, Agostinho ressaltava que o ideal e a prática da vida comum tinham sido conhecidos pela Igreja primitiva dos Apóstolos antes - e de preferência - que o ascetismo rigoroso dos monges do deserto. Ressalva feita à forma de vida eremítica, a perspectiva de Agostinho contrastava com as posturas mais comuns nas cidades ocidentais frente à propagação do monasticismo no século IV.

A concepção agostiniana do ideal monástico remeteria, claramente, ao conjunto das formulações do bispo de Hipona sobre a Igreja católica, seu caráter soteriológico e sua atuação no mundo (MARKUS, 2007, p. 103 e seguintes). Na Igreja militante, o homo viator encaminhava- se à sua verdadeira pátria - o Reino de Deus -, por intermédio da prece, liturgia e do ministério

Trata-se da Epístola 211, destinada a mulheres religiosas, e da obra Regula ad servos Dei, contendo os princípios básicos da vida religiosa para varões - várias ordens acabaram tomando este último documento como regra de vida. 
dos sacramentos; a consecução desse objetivo encontrava-se, por seu turno, subordinada ao caráter institucional da ecclesia - dotada de aparato administrativo e personalidade jurídica, ligada à distribuição de bens materiais e à organização do Estado.

Os desdobramentos do fenômeno da imersão do cristianismo no saeculum, a partir do início do século IV, seriam assimilados de maneiras variadas no mundo mediterrâneo, conforme, a saber, as práticas e lideranças das diversas comunidades. Em sua contenda com os donatistas, ${ }^{4}$ Agostinho formularia um amplo conceito de Igreja, destinado a conciliar o seu caráter sobrenatural com as suas atribuições terrenas. Ao longo de sua obra, descreve a comunidade concreta de cristãos que constitui a Igreja como um corpo misto de santos e maus, recusando, portanto, a ideia desta como uma elite de eleitos em um mundo profano - De civitate Dei, L.XX, cap. 9. Em algumas passagens, as Duas Cidades - terrestre e celeste - conviveriam no Império e na Igreja, sendo esta última identificada à Cidade de Deus aqui e agora, ao passo que o primeiro se encontrava, da mesma forma, indiferentemente aberto às Duas Cidades - De civitate Dei, L.XX, cap. 9.

\section{São Boaventura e a Igreja Militante: a socie- dade humana e os ofícios divinos}

4 O donatismo é uma heresia que remonta à primeira metade do século IV, a partir da ação do bispo Donato, no Norte da África. Um de seus fundamentos consistia na busca por proteger sua igreja do contato com os chamados traditores, aqueles que haviam abandonado o cristianismo durante a Grande Perseguição de Diocleciano (303-305). A vertente sobreviveria até a expansão islâmica dos séculos VII e VIII, sustentando a concepção da Igreja como "elite" perseguida, a saber, um conjunto de fiéis, santo e dotado de tarefas estranhas ao mundo hostil da sociedade secular que o cercava. Os católicos deveriam, por sua vez, ser vistos como apóstatas, comprometidos com as autoridades seculares - as mesmas que tinham perseguido o cristianismo -, e representariam uma traição permanente à tradição dos mártires (MARKUS, 2007, p. 92-122).
A concepção agostiniana, para o homem, de um estado propriamente social em pleno Paraíso terrestre, teria como consequência a atribuição de instituições aos homens quando da Criação. Dessa forma, vigorariam, no Paraíso, enquanto criações divinas, a organização social, o matrimônio e a sexualidade. Por extensão, passariam integrar o conjunto de instituições paradisíacas - na mesma medida em que o debate acerca da pobreza e dos poderes ganhava corpo, ao longo da Idade Média - aspectos tais como a propriedade e o poder. centrais para a formulação da identidade da Ordem Franciscana.

\section{Do conhecimento à humildade}

Definido como "[...] o ponto culminante da Escola Franciscana do século XIII [...]" (BOEHNER; GILSON, 2004, p. 421) e "[...] antes adversário de Aristóteles que da Filosofia [...]" (LIBERA, 1993, p. 404), Boaventura estabeleceria, ao longo de sua atuação na Universidade de Paris - e ao lado de Tomás de Aquino, o mestre dominicano -, uma filosofia "do Cristo" (LIBERA, 1993, p. 404), não completamente imune à influência do aristotelismo averroísta (BOEHNER; GILSON, 2004, p. 421). No entanto, a matriz para a construção desse quadro do pensamento permaneceria, sempre, agostiniana, marcada por aspectos neoplatônicos (DE BONI, 2003, p. 196).

Ao propor o conhecimento como caminho para se atingir Deus, Boaventura estabeleceu a necessidade da Filosofia, enquanto "Ciência" subordinada à Teologia, sendo esta última a única capaz de conduzir à Mística, a saber, ao encontro da alma com Deus. Nessa proposição, destacava-se a Sabedoria como fundamento da contemplação mística, conforme a concepção de Agostinho: sendo o único conhecimento possível aquele de Deus, o filósofo deveria devotar-lhe a caritas, como forma de apreender a realidade: "Por isso a fé é o ponto de partida para todo conhecimento, inclusive para o conhecimento filosófico" (Sermo IV, 15; 
t. 5, p. 571, tradução nossa). ${ }^{5}$ O Amor de Deus, motor da especulação, instigava a razão: "Pois aquele que crê deseja, pelo amor, abraçar, com todas as forças da alma, o objeto de sua fé, e penetrá-lo com a razão" (I Sent. Prooem. 2; t. I, p. 11, tradução nossa). ${ }^{6}$ A relação entre a Filosofia e a fé produziria, em Boaventura, uma ampla e, ao mesmo tempo, profunda doutrina do conhecimento: "A história do pensamento humano [...] é a história de sua lenta e penosa progressão, pelos mais diversos equívocos, em direção a uma verdade escondida que a fé, enfim, descobre" (GILSON, 1953, p. 151).

Seguindo de perto a doutrina agostiniana, Boaventura acreditava que a alma humana fora concebida para conhecer Deus - identificado ao Bem infinito -, para o que dispunha da fé, sinalizada a um conhecimento imperfeito embora correto. Sendo todo conhecimento aquele de Deus, a Filosofia encontrava-se a serviço da realização final e completa do Amor de Deus no homem, concretizada quando do encontro da alma com Deus. O amor perfeito - aquele concluído em sua completude - esperava o ser humano ao final da peregrinação, a saber, do itinerário da alma para Deus. O homo viator, na Igreja militante, tinha como finalidade e destino a re-união com o Criador, a reconciliação do homem com a sua natureza primeira, anterior à Queda: "quo modo homo per alias res tendat in Deum" - Itinerarium mentis in Deum, cap. I, item IX. O tempo não consistia, portanto, em medida de duração propriamente dita, mas antes, precisava ser concebido como "tempo da criação" e "tempo da salvação":

Assim, para Boaventura, a História é sempre considerada a partir de uma perspectiva de fé, em outras palavras, como História da Salvação, de modo que a sua reflexão sobre a mesma constitui-se numa verdadeira e própria Teologia da História (GOMES, 2001, p. 57-59).

5 "[...] ordo enim est, ut inchoetur a stabilitate fidei". "Christus unus omnium Magister".

- "Miro enim modo anima delectatur in intelligendo quod perfecta fide credit".
Como decorrência, a escatologia boaventuriana consistia em um desdobramento da sua visão do ser humano. Por ter sido criado como capax Dei, como um projeto aberto (GOMES, 2001, p. 72), o ser humano vivia uma existência marcada por uma tensão, a saber: somente participando plenamente da vida divina encontraria a sua plena realização (GOMES, 2001, p. 72). Como decorrência, a natureza paradisíaca configurava-se como "[...] o estado da humanidade assim como deveria ser, e serve de parâmetro quando se fala do homem, tal como é" (DE BONI, 2003, p. 197).

Deus criara o homem na retidão, mas o homem, por sua própria culpa, decaíra de sua dignidade original, perdendo o estado de inocência (PALMERI, 2013, p. 58). Enquanto viator, a criatura humana experimentara as consequências de seus novos limites. O homem, pecador e imperfeito - a não perfeição provinha da condição de pecador, pois essa determinava a incompletude - buscava a superação da condição imperfeita, a fim de recuperar a sua natureza primeira Itinerarium mentis in Deus, cap. 1, item VII:

\footnotetext{
Portanto, aquele que quer elevar-se a Deus deve evitar o pecado que desfigura a natureza e deve aplicar as faculdades naturais [...] para adquirir, pela oração a graça que reforma, por uma vida santa a justiça que purifica, pela meditação a ciência que ilumina, pela contemplação a sabedoria que aperfeiçoa.
}

Para tanto, o homem deveria reconhecer-se humilis - humilde e, primariamente, "lodo da terra" (Gn 2,7) -, e o conjunto dos frades assumia a condição humana no modo pobre de vida da Ordem e em seus denominativos pauperes e minores. A humildade consistia, para Boaventura, em condição para a sabedoria, pois se encontrava na base da atitude com vistas ao conhecimento - "[...] mas ninguém chega a um perfeito conhecimento de Deus a não ser por meio de uma notícia verdadeira e correta de si; nem se conhece corretamente aquele que não se dá conta de sua própria nulida- 
de"7 (De perfectione evangelica, BAC, 1949, p. 22, tradução nossa). Além disso, fundamentava a própria justiça, a qual se cumpria mediante "[...] honra e reverência, a cujo ato predispõe especialmente a humildade"s (De perfectione evangelica, BAC, 1949, p. 24, tradução nossa). Por fim, a humildade era, no entender do doutor seráfico, morada da graça:

Pois a graça torna o homem grato a Deus; e é agradável a Deus aquele que reconhece o dom da divina dignação e condescendência; entretanto, ninguém conhece essas coisas a menos que esteja consciente de sua indignidade; e aquele é verdadeiramente humilde: por isso, a graça do Espírito Santo repousa somente sobre os humildes' (De perfectione evangelica, BAC, 1949, p. 26, tradução nossa).

O ato próprio da humildade era a auto-humilhação - externa e interna. Essa última tinha origem no reconhecimento da culpa, uma vez que a Queda havia sido motivada pelo orgulho - era necessário, portanto, manifestar o desprezo de si não apenas interiormente, mas também à vista de todos. O exercício da humilhação permitia aperfeiçoar a humildade, de forma que Boaventura retomou os padres sob o ponto de vista da doutrina e liturgia:

Donde, sobre as palavras de João, capítulo 13: Deveis lavar os pés uns dos outros. Glosa: "Excita-se a humildade do coração daquele que se inclina até os pés, ou, se já a tem no coração, confirma-se a afeccão da humildade". E afirma Bernardo na epístola a Ogério: "A humildade, à qual certamente conduz a humilhação, é o fundamento de todo o edifício espiritual; pois a humilhação é caminho para a humilda-

7 "Nullus autem pervenit ad plenam notitiam Dei nisi per veram notitiam sui et rectam; nec recte se ipsum cognoscit qui suam ipsius nihilitatem non attendit".

8 "[...] honor et reverentia; et ad hoc reddendum praecipue disponit humilitas".

9 "Nam gratia facit hominem Deo gratum; gratus autem est Deo qui cognoscit divinae dignationis et condescensionis donum; nullus autem hoc cognoscit nisi circunspector suae indignitatis". de como também o é a paciência para a paz, o estudo para a ciência. Se te apetece a virtude da humildade, não fujas da via da humilhação; pois se não podes ser humilhado, não poderás atingir a humildade" "IO (De perfectione evangelica, BAC, 1949, p. 28, tradução nossa).

A passagem do lava-pés foi, ainda, retomada quando da defesa da pobreza franciscana na Apologia pauperum: Cristo teria, assim, demonstrado que era e devia ser chamado de Mestre e Senhor, a fim de que, "[...] declarando-se rei excelso, induzisse os discípulos a imitá-lo na humildade que lhes havia ensinado"l (Apologia pauperum contra calumniatorem, BAC, 1949, p. 586, tradução nossa). Conquanto fosse expressão da polêmica com os mestres seculares da Universidade de Paris, a Apologia pauperum também associava a humildade à recusa das dignidades - temporais ou eclesiásticas -, a fim de exaltar o modo de vida dos religiosos:

Se, pois, Cristo, ao fugir ao reino, deu a seus seguidores o exemplo de fugir à glória, ao favor e à prosperidade, e essas coisas não só se encontram nas dignidades mundanas, mas também nas eclesiásticas, consta que é próprio da humildade fugir a elas para a perfeita imitacão da humildade de Cristo'2 (Apologia pauperum contra calumniatorem, BAC, 1949, p. 586, tradução nossa).

10 "Unde super illud Iohannis decimo tertio: Et vos debetis alter alterius lavare pedes; Glossa: 'Qui ad pedes inclinatur, ei in corde humilitas excitatur; vel si iam est in corde, confirmatur humilitatis affectus.' Et Bernardus in quadam epistola ad Ogerium: 'Humilitas, ad quam utique ducit humiliatio, totius est fabricae spiritualis fundamentum; siquidem humiliatio via est ad humilitatem, sicut patientia ad pacem, sicut lectio ad scientiam. Si virtutis appetis humilitatis, viam non refugias humiliationis; nam, si non potes humiliari, non poteris ad humilitatem provehi".

11 "[...] per declarationem regiae celsitudinis discípulos induceret ad imitationem ostensae humilitatis". "Apologia pauperum contra calumniatorem".

12 "Si igitur Christus in fugiendo regnum se sequentibus exemplum dedit fugiendi gloriam, favorem et prosperitatem; et haec non tantum reperiuntur in dignitatibus mundanis, sed etiam ecclesiasticis; constat quod humilitatis est haec refugere ad perfectam humilitatem Christi imitationem". 
Em sua contenda contra os mestres seculares - com destaque para Geraldo de Abbéville -, Boaventura contestou a tradicional interdição do ministério da predicação aos monges, consagrada a partir de um modelo hierárquico que remontava a Dionísio, o pseudoareopagita: "monachos in ecclesiastica hierarchia non habere statum perficientium, sed perficiendorum" (Apologia pauperum contra calumniatorem, BAC, 1949, p. 668). O doutor seráfico apoia-se em o próprio vir hierarchicus para concluir que "[...] é próprio dos monges purificar-se, iluminar-se e aperfeiçoar-se [...]" (Apologia pauperum contra calumniatorem, BAC, 1949, p. 668, tradução nossa), assim como o é também para toda a ordem sacerdotal. A profissão de fé dos pobres de Boaventura aproximava-se daquela dos monges, aos quais se identificavam pela via contemplativa e, ulteriormente, pela realização de obras atinentes ao clero - tais como a pregação - por intermédio da autoridade dispositiva do Papa, a qual transcendia todos os direitos positivos: "cuius dispositionis auctoritas iura omnia positiva transcendit" (Apologia pauperum contra calumniatorem, BAC, 1949, p. 668).

Era própria do religioso, tanto para Agostinho quanto para Boaventura, a busca de uma perfeição contemplativa que não se realizava, entretanto, a despeito da "via ativa" no mundo e tampouco de sua organização social. A condição do monge-peregrino passava, preferencialmente, pela vida cenobítica, associada ao voto de pobreza que caracterizava a sua professio. A vida cenobítica foi recomendada aos frades por Boaventura, e reproduziria uma dinâmica social no cotidiano dos conventos. Essa vida propriamente social comportava intercâmbios com a sociedade secular, especialmente as populações citadinas da Itália Central do século XIII - o saldo das trocas, materiais e simbólicas, porquanto não fosse sempre positivo, jamais anulava a sua necessidade e legitimidade. $\mathrm{Na}$ origem do próprio ideário franciscano - e em função do papel dos frades na sociedade -, subjaz a criação de um vocabulário voltado, sobretudo, para a realidade urbana, o que implicava em renunciar à linguagem sacral e aproximar-se das categorias sociais:
O desejo de eficácia do franciscanismo frente à nova sociedade impõe-the uma linguagem, um vocabulário dotado de relação com a realidade, sobretudo com a realidade social, em sua estrutura de grupos. Ao mesmo tempo, o desejo de Francisco e seus discípulos de dirigir- se ao conjunto da sociedade os conduz a utilizar sistemas de denominação capazes de dar conta de todas as categorias sociais (LE GOFF, 1999, p. 107).

A inserção das ordens mendicantes, e particularmente dos franciscanos, nas cidades atendia, por seu turno, à necessidade da cura animarum imposta pela crescente urbanização verificada ao longo das primeiras décadas do século XIII. Esse movimento, da periferia em direção ao centro de cada cidade, traria o seu quinhão de benefícios para a população urbana, ao mesmo tempo em que contribuiria para delinear os contornos das novas ordens:

\footnotetext{
Porque na raiz da experiência mendicante encontramos o duplo jogo de "fuga" e de "fundação" de uma espécie de cidade de Deus. É a mesma dualidade presente no movimento do monacato feudal, mas agora expressa de forma diferente: a fuga é o distanciamento voluntário do claustro monacal; não é fuga do mundo, mas fuga da organização estável e autossuficiente do monastério. E o ideal de fundação consiste em fazer-se presente de forma itinerante na cidade, nos centros urbanizados, para viver em dependência "mendicante" provisória, da assistência oferecida pelos membros da sociedade (CRESTA, 2010, p. 144)
}

Homo viator, o frade não representava uma exceção: a proximidade da população do entorno e a condição inerente de pobreza faziam lembrar a própria condição humana, inapelavelmente pecadora. Em sua vocação pregadora, a Ordem Franciscana atuava no mundo e, ao mesmo tempo, era representação do homem no mundo, na medida em que se identificava à condição precária da natureza humana: a 
tríade frade-pobre-pecador, ao mesmo tempo em que profissão de humildade, era transfiguração da linguagem dos salmos, na qual o pobre assumia a identidade do pecador, inseparável da natureza humana após a Queda.

As cidades celeste e terrestre não eram, afinal, incomunicáveis, tampouco excludentes: a atuação dos frades no século valorizava a Igreja Militante, e, em um dado intervalo espaço-temporal, abria as portas da Cidade celeste. A Cidade dos homens podia, portanto, ser situada na geografia da Cidade celeste prenunciada. Para que a convergência tivesse êxito, em muito contribuiria a retomada de valores produzida a partir da vida citadina do século XIII: entre a cidade romana agostiniana e a cidade burguesa medieval, verificavam-se algumas identidades: lugar de todas as trocas, ambiente para a circulação de ideias, sede das instituições e da autoridade pública.

\section{Entre a intuição e as instituições}

Nascido João de Fidanza, em Bagnoregio, no ano de 1221, Boaventura ingressou na Ordem Franciscana por volta de 1238, e partiu para Paris, onde seguiria as aulas de Alexandre de Hales, considerado o seu grande mestre e cuja Cátedra viria a ocupar a partir de 1248. Receberia o grau de doctor no ano de 1257, juntamente com o dominicano Tomás de Aquino, mas viria a abandonar o magistério naquele mesmo ano, pois se tornara ministro-geral de sua Ordem. Morreu aos 15 de julho de 1274, deixando como legados a pacificação temporária de querelas internas, o paradigma de todo o pensamento filosófico e teológico franciscano da Idade Média e uma concepção de Ordem profundamente vinculada à doutrina agostiniana sobre a natureza humana.

Conforme De Boni (1998, p. 27), Agostinho foi citado 3.050 vezes ao longo da obra de Boaventura, com destaque ao De Trinitate, aos tratados bíblicos Sobre o Evangelho de São João, Sobre o Gênesis e Sobre os Salmos, o De civitate Dei e os Sermões. Ao passo que uma matriz agostiniana comum teria moldado, em linhas gerais, todo o pensamento medieval, os aspectos que identificam Boaventura - consequentemente, os franciscanos - a Agostinho evidenciam-se, inclusive, no detalhe. $O$ paradigma agostiniano encontra-se não apenas difuso, como também expresso em sua especificidade no discurso franciscano e na "personalidade" da Ordem:

\footnotetext{
Entre Boaventura e Agostinho há uma afinidade de gênios como raro sói acontecer. Tanto para um como para outro, a visão cristã do mundo expressa-se por uma compreensão unitária do saber e da vida, coroada por uma leitura mística da existência (DE BONI, 1998, p. 27).
}

Porquanto não pudesse ser identificado como substância - devido à inexistência do mal enquanto princípio absoluto ${ }^{13}-$, o pecado era defeito e corrupção, "[...] pelo qual se corrompe o modo, a espécie e a ordem na vontade criada" - Breviloquium, cap. III, item I. Sendo a corrupção algo que só se encontra no bem, o pecado, enquanto corrupção, "[...] não consiste em apetecer as coisas más, mas em apartar-se das melhores" - Breviloquium, cap. III, item I. Ao examinar a forma pela qual a corrupção, a partir da Queda dos primeiros pais, entrara no mundo, Boaventura enunciou a premissa segundo a qual "Deus criou o homem em ambos os sexos - masculino e feminino - na felicidade do Paraíso" - Breviloquium, cap. III, item II. Homem e mulher e, portanto, seres sexuados, os quais transmitiriam o pecado ao gênero humano, de forma inapelável e incancelável: "O gênero humano corrompe-se pelo pecado original da seguinte maneira: todo aquele que nasce por geração nasce filho da ira (Ef2,3), por estar privado da retidão da justiça original" Breviloquium, cap. III, item V.

Com a Queda, a sensualidade passara a ser desordenadamente movida, ao contrário do

13 Boaventura segue Agostinho de muito perto em sua negação da existência do mal. Trata-se de tópica agostiniana, manifesta em sua postura contrária aos maniqueus - De civitate Dei, L.XII, cap. II. 
estado de inocência, quando era movida pela razão: "Agora, como a sensualidade contradiz a razão, queiramos ou não, inevitavelmente cometemos algum pecado venial pelos primeiros movimentos [...]" - Breviloquium, cap. III, item VIII. E ainda, a partir da Queda, o homem, corrompido e imperfeito, passara a mover-se em meio a instituições corrompidas e imperfeitas. Criadas e estabelecidas na sociedade paradisíaca primordial, as instituições decaíram assim como o homem, marcando o início da peregrinação em direção ao reencontro com - Criador. Assim, de acordo com a concepcão franciscana, o domínio comum a todo o gênero humano fora dado por Deus a Adão e Eva, ao passo que o domínio particular se introduzira a partir da Queda. A propriedade - o dominium - e o poder - forma de exercício do dominium -, porquanto tivessem lugar na sociedade paradisíaca, ali se manifestaram em estado de perfeição: teriam decaído ao estado imperfeito a partir da queda do próprio do homem.

Quando Deus o criou à sua imagem e semeIhança, e concedeu-lhe a graça de conhecê- Lo por meio do dom dos hábitos da virtude, a condição do homem era de retidão - rectitudo (PALMERI, 2013, p. 16). A Queda introduzira o aspecto da imperfeição, extensivo às instituições próprias da humanidade. A título de primeiro exemplo, figura o matrimônio, considerado como a primeira instituição humana estabelecida por Deus na sociedade paradisíaca Breviloquium, cap. IV, item XIII:

Essa união não somente se realiza depois do pecado, pois antes dele também já existia, mas, então, o sacramento do matrimônio foi instituído como dever, e agora, não só como dever, mas também como remédio contra a concupiscência.

Da mesma forma, a propriedade, na literatura boaventuriana, deveria passar pelo expurgo da culpa, por intermédio do exercício voluntário da pobreza. Denominada penúria exterior, a pobreza, sobretudo em sua modalidade franciscana, servia ao extermínio do pecado, ao exercício da virtude perfeita, ao júbilo interior e à propagação da pregação evangélica. Porquanto existente, em sua forma perfeita, na sociedade paradisíaca, a propriedade teria sido recusada por Cristo com a finalidade de pavimentar o caminho da redenção, pois, "[...] ainda que as riquezas, tanto comuns quanto próprias, possam ser havidas e possuídas sem pecado, não obstante, renunciar a elas é próprio da perfeição"14 (Apologia pauperum contra calumniatorem, Bac, 1949, p. 578, tradução nossa).

A possibilidade de superação da imperfeição inerente ao dominium viria a ser idealizada, na Ordem, no século XIII, por intermédio do recurso à categoria do usus, para cujo suporte teórico concorrera a obra de Boaventura - a separação entre o uso e a propriedade, apenas esboçada por Gregório IX (1227-1241), seria confirmada por Nicolau III, por intermédio da bula Exiit qui seminat, de 14 de agosto de 1279. Na Apologia, o doutor seráfico enumera quatro aspectos a respeito do domínio das coisas temporais, a saber: propriedade, tenência, usufruto e uso simples. Ora, a superação da imperfeição inerente ao pecado viabilizava-se pela adoção do último modo, a saber, o usus simplex, aquele estritamente indispensável à vida humana:

\footnotetext{
Mas foi conveniente àquela profissão que fez espontaneamente o voto de seguir a Cristo na extrema pobreza renunciar universalmente ao domínio das coisas e contentar-se com o uso estreito das coisas alheias ou que foram concedidas ${ }^{15}$ (Apologia pauperum contra calumniatorem Bac, 1949, p. 642, tradução nossa).
}

O homem, imagem divina a partir de sua alma racional, era semelhança à vida divina. Por essa razão, o dominium exercido pelo homem sobre a realidade do mundo decorria do dominium exercido por Deus sobre toda a criação. O domínio

\footnotetext{
14 "Licet autem divitiae tam communes quam próprias haberi et possideri valeant absque peccato, tamen eas relinquere perfectionis est".

15 "Verum ei professioni, quae sponte devoti Christum in
} 
humano não deveria, portanto, converter-se em forma de opressão, na medida em que deveria consistir em experiência capaz de reconduzir o mundo sensível à beatitude; em contrapartida, não deveria converter o homem em escravo do exercício daquele mesmo domínio, introduzindo uma relação distorcida com a posse das coisas e com o governo do mundo (PALMERI, 2013, p. 55).

Por isso, a forma mais perfeita de domínio humano era a paupertas, por consentir o pleno exercício da liberdade e, em consequência, reconstituir a imago divina, ocultada à humanidade a partir do pecado original (PALMERI, 2013 , p. 55). A rectitudo e a similitudo vigentes no estado de inocência humana teriam sofrido, então, uma deformação e um distanciamento (PALMERI, 2013, p. 55), que supunham um movimento subsequente de reunião com o princípio e com o uno - a unidade em Deus, ideal próprio do cristão, era favorecida pela paupertas, na medida em que esta enunciava o desprendimento de si.

\section{Da propriedade à pobreza: soluções para o dilema da humanidade após a Queda}

A pobreza consistia, portanto, no exercício de uma forma de perfeição que aproximava os homens da vida evangélica. Era recomendável ao conjunto da cristandade, ao mesmo tempo em que obrigatória aos frades, os quais, de acordo com Boaventura, eram modelo e exemplo do verdadeiro pobre, o qual:

[...] por Cristo, abandonou e repartiu não somente aquilo que tinha, mas também aquilo que podia desejar, é contente com - pouco e restrito [que obtém] para a sustentação da natureza, e será, segundo esta razão, minimamente miserável, pelo pouco que recebe, e maximamente

extrema paupertate sectari, condecens fuit universaliter rerum abdicare dominium arctoque rerum alienarum et sibi concessarum usu esse contentam". santo, pelo muitíssimo que dá ${ }^{16}$ (Apologia pauperum contra calumniatorem, Bac, 1949, p. 696, tradução nossa).

E ainda, os frades de Boaventura eram, segundo o mestre e ministro-geral, "homens evangélicos" - viri evangelici -, na medida em que se constituíram em defensores da causa dos pobres por meio da renúncia a seus haveres e do engajamento na salvação das almas, "[...] porque, movidos por abundante misericórdia, deram seus bens temporais para sustentar os corpos dos pobres, e dispensam continuamente bens espirituais para o sustento das almas"17 (Apologia pauperum contra calumniatorem, Bac, 1949, p. 702, tradução nossa).

Ideal identificado pela Regra e pela Escola franciscana ao próprio modo de vida de Cristo e dos apóstolos, a pobreza absoluta, a partir da renúncia de toda forma de propriedade, retendo das coisas apenas o seu uso restrito "[...] renúncia de toda tenência transitória com penúria e indigência do próprio sustento: e esta compete aos apóstolos e varões apostólicos"18 (Apologia pauperum contra calumniatorem, Bac, 1949, p. 518, tradução nossa), representava, para o conjunto da cristandade, reconciliação com a natureza primeira do homem e possibilidade de redenção da humanidade.

Se, contudo, a pobreza articulava-se ao projeto de salvação - por ligar-se indissoluvelmente, conforme os franciscanos, à forma de vida e ao ensinamento de Cristo e, portanto, à redenção da humanidade -, a propriedade, em sua forma privada, decorria das vicissitudes resultantes da Queda: a posse de bens

16 "[...] verus pauper, qui propter Christum omnia deserit et dispergit, non solum quae habuit, sed etiam quae concupiscere potuit, et paucis ac modicis est ad sustentationem naturae contentus, erit secundum hanc rationem acceptione parcissima minime miser et donatione largiflua máxime beatus".

17 "[...] quoniam ex abundante misericórdia temporalia bona largiti sunt ad sustentanda corpora pauperum, et spiritualia bona continue largiuntur ad sustentationem animarum"

18 "[...] in abdicatione omnis transitoriae facultatis cum penuria et indigentia opportunae sustentationis, et haec competit apostolis et apostolici viris". 
restritiva a indivíduos deveria ser entendida como necessidade - e não como meramente acidental. Nesse sentido, a propriedade privada dos bens havia sido permitida por Deus a fim de prover a organização das sociedades humanas, tendo em vista o pecado, que reduzira o homem a um estado imperfeito. Boaventura acompanhava Alexandre de Hales, para quem, no estado de natureza decaída, era bom que algumas coisas fossem particulares, a fim de afastar o risco de que os maus se apoderassem de tudo, deixando os bons em estado de indigência (DE BONI, 2003, p. 198).

A propriedade comum, por seu turno, era pertinente ao estado natural de perfeição do homem, segundo o qual Deus ordenara os bens a fim de prover o sustento das pessoas. Boaventura adverte, a esse respeito, "[...] que todas as coisas devam ser comuns é um ditame segundo o estado de natureza instituída; que algumas sejam particulares é um ditame segundo o estado de natureza decaída, para evitar contendas e disputas" (DE BONI, 2003, p. 198). Por essa forma, o estado monástico representava, do ponto de vista da organização dos haveres, uma tentativa de reproduzir a ordem paradisíaca. $O$ estado dos frades, por seu turno, definido pela pobreza absoluta, encontrava-se, igualmente, em estreita relação com a Queda: na medida em que esta determinaria um estado decaído da sociedade e das instituições humanas, a ausência de propriedade remontaria aos primeiros padres ao mesmo tempo em que apontaria para a realização da perfeição evangélica - e, portanto, para o caminho da redenção da humanidade.

\section{Considerações finais}

Em sua elaboração do ideal monástico ao Ocidente cristão tardo-antigo, Agostinho estabelecera, como aspecto comum e indissociável do homem, a marca do pecado. Em sua defesa e interpretação do projeto franciscano, Boaventura de Bagnoregio retomou a reflexão patrística a fim de estabelecer a imperfeição da condição humana, associada à própria condição de seus frades - refletida nos termos de que o grupo se apropriara desde os tempos de Francisco: "pequenino", humilis, menor. O homo viator, pobre e peregrino pela definição de sua própria condição, constituía a Igreja Militante, que deveria - como exigência de sua própria essência - cumprir a sua trajetória rumo à Igreja Triunfante.

Os frades de Boaventura reproduziam a Cidade dos Homens, por sua condição exterior de vida - que evocava o sofrimento e o pathos que os fazia similares a Cristo -, ao mesmo tempo em que constituíam, já sobre a terra, pela elevação da vida interior, a Cidade de Deus. Da mesma forma, a Igreja que Agostinho descrevera supunha a coexistência das duas cidades não apenas na vida humana, como também em suas instituições - ainda que, por definição, imperfeitas.

Em sua forma de vida, o grupo manifestava, mesmo que de forma difusa, o ideal agostiniano que concebia a história humana como trajetória dos homens em direção ao retorno, à reconciliação com sua pátria original - o Reino dos Céus, no qual haviam sido criados como anjos. Boaventura, por seu turno, defendera o conhecimento de si como aspecto do conhecimento de Deus, sendo a trajetória do conhecer identificada ao caminho - ou itinerário - para a perfeição. A via para a Redenção combinava, portanto, o conhecimento à pobreza, e ambos se fundamentavam na fé - esta última era a única possibilidade de retorno, na busca do homem pela perfeição perdida.

\section{Fontes}

AGOSTINHO DE HIPONA. Confessiones, L.I, cap. 11 Confessiones, L.VI, cap. 24.

De civitate Dei, L.XII, cap. 2.

De civitate Dei, L.XIV, cap. 10

De civitate Dei, L.XX, cap. 9

AGOSTINHO, SANTO. Confissões. Trad. Maria Luiza Jardim Amarante. São Paulo: Paulus, 1997.

AGUSTÍN, SANTO. La Ciudad de Dios. Trad. Jose 
Cayetano Diaz de Beyral. 2 t. Buenos Aires: Club de Lectores, 2007.

BOAVENTURA DE BAGNOREGIO. Brevilóquio. In: BOAVENTURA DE BAGNOREGIO: escritos filosófico-teológicos. Trad. Luís Alberto De Boni; Jerônimo Jerkovic. Porto Alegre, RS: EDIPUCRS, 1998a.

Itinerário da mente para Deus. In: BOAVENTURA de Bagnoregio: escritos filosófico-teológicos. Trad. Luís Alberto De Boni; Jerônimo Jerkovic. Porto Alegre, RS: EDIPUCRS, 1998b.

Breviloquium. Disponível em: <https://archive.org/stream/breviloquiumOObona\#page/n23/ mode/2up>. Acesso em: 28 set. 2018.

Itinerarium mentis in Deum. Disponivel em: <http://www.thelatinlibrary.com/bonaventura.itinerarium.html>. Acesso em: 28 set. 2018.

Apologia pauperum contra calumniatorem. In: Obras de San Buenavnetura. t. 6. Madrid: BAC, 1949a.

De perfectione evangélica. In: Obras de San Buenavnetura. t. 6. Madrid: BAC, 1949b.

GREGÓRIO MAGNO. Sancti Gregorii Magni - Regula Pastoralis. In: MIGNE, J. P. Patrologiae cursus completus.t. 77. Paris: [s.n.], 1869. (Col. 25; Series Latina).

\section{Referências}

$\mathrm{BICHKOV}, \mathrm{O}$. The nature of theology in duns scotus and his franciscan predecessors. Franciscan Studies, v. 66, p. 5-62, 2008.

BOEHNER, P.; GILSON, E. História da Filosofia Cristã Trad. Raimundo Vier. Petrópolis, RJ: Vozes, 2004.

BROWN, P. The body \& society: men, women \& sexual renunciation in early Christianity. New York: Columbia University, 2008.

The rise of Western Christendom: triumph and diversity, A.D. 200-1000. Malden: Blackwell, 2007.

Antiguidade tardia. In: ARIĖS, P.; DUBY, G. (Org.). História da vida privada: do Império romano ao ano mil. Trad. Hildegard Feist. v. 1. São Paulo: Companhia das Letras, 1989. p. 225-300.

CONSTABLE, G. The Reformation of twelfth century. Cambridge: CUP, 2002.
CRESTA, G. Valor y sentido del conocimiento en los órdenes mendicantes del siglo XIII. Acta Scientiarum, Maringá, PR, v. 32, n. 2, p. 141-151, jul./ dez. 2010.

DE BONI, L. A. De Abelardo a Lutero: estudos sobre Filosofia prática na Idade Média. Porto Alegre, RS: EDIPUCRS, 2003.

Apresentação. In: BOAVENTURA de Bagnoregio: escritos filosófico-teológicos. Trad. Luís Alberto De Boni; Jerônimo Jerkovic. Porto Alegre, RS: EDIPUCRS, 1998.

GILSON, E. La philosophie de Saint Bonaventure. Paris: Vrin, 1953

GOMES, F. C. A Teologia da história no de perfectione evangélica de São Boaventura de Bagnoregio. Oracula, n. esp., p. 57-75, 2011.

LE GOFF, J. Saint François d'Assise. Paris: Gallimard, 1999.

LIBERA, A. La philosophie médiévale. Paris: PUF, 1993. MARKUS, R. A. The latin fathers. In: BURNS, J. H. (Org.). The Cambridge history of medieval political though c.350-c.1450. Cambridge: CUP, 2007.

O fim do cristianismo antigo. Trad. João

Rezende Costa. São Paulo: Paulus, 1997.

MARROU, H.-I. Décadence romaine ou Antiquité tardive? IIIe.-IVe. siècles. Paris: Seuil, 1977.

PACAUT, M. Les ordres monastiques et religieux au Moyen Âge. Tours: Nathan, 1993.

PALMERI, P. Libertà e povertá: uma lettura dell'Apologia pauperum di Bonaventura da Bagnoregio. 2013. 313 f. Tese (Doutorado)-Università degli Estudi di Salerno, Salerno, Italia, 2013.

PEREIRA, V. S. Crônica de uma morte anunciada: a queda de Roma. In: OLIVEIRA, F. de et al. (Coord.). A queda de Roma e o alvorecer da Europa. Coimbra; Madrid: Imprensa da Universidade de Coimbra, 2013. p. 11-26. 
